\title{
Challenges to the development of the world's first nondestructive inspection system
}

\author{
- Development of an inspection system with laser ultrasound \\ and a cold cathode X-ray source -
}

\author{
Bo Wang, Junji TAKatsubo, Norio SaIto*, Xiaojun LIU and Shuichi SuzUKI
}

[Translation from Synthesiology, Vol.10, No.2, p.75-86 (2017)]

\begin{abstract}
The social and industrial infrastructure built for the 1964 Tokyo Olympics, during a period of high economic growth, has become old. This infrastructure urgently needs inspection for the success of the 2020 Tokyo Olympics. As an AIST Start-up, we are conducting research and development of a new nondestructive inspection system based on the world's first visualization technology using laser ultrasound and compact X-ray technology with carbon nanostructure cold cathode X-rays. Here we describe various challenges for its development.
\end{abstract}

Keywords : Nondestructive inspection, laser ultrasound, X-ray inspection, visualization, miniaturization, image processing, secular change

\section{Introduction}

Currently, Japan is facing a problem of aging social and industrial infrastructures that were built during the rapid economic growth period. Various inspection devices are used for the maintenance inspection of such infrastructures, but in most cases, these products are imported from overseas.

As a technology transfer venture company of AIST, we are spending our efforts to research, develop, and achieve product realization of new nondestructive inspectors to inspect the social and industrial infrastructures, and to make contribution to safety and security.

One of our efforts is a laser ultrasonic visualization inspector (LUVI). This is a device by which thermal stress ultrasound is generated by laser-scanning the surface of the object to be inspected, and the behavior of ultrasound propagation is visualized. It is the first of its kind in the world. This device has the characteristics that follow: (1) it allows nondestructive inspection of objects with complex shapes, and (2) it allows inspection of objects at high speed from a distance.

Another effort is a compact X-ray inspector that fits in the palm of a hand, can be driven even by dry cell batteries, and is equipped with a small power-saving cold cathode X-ray tube. This device has the characteristics that it is compact and lightweight, can generate X-ray instantly without preheating, is power-saving so it can be driven by an AA battery, and has a long lifespan.
In this report, the development of LUVI and a dry-celloperated compact X-ray inspector, as well as their application to various inspections will be explained.

\section{LUVI and its application to nondestructive inspection}

Laser ultrasound is a technology to generate ultrasound in an object and to conduct inspection without contact, using laser beams. The sending/receiving of ultrasound can be done in a nondestructive manner from a distance, and this enables inspection of objects that were difficult to inspect using conventional devices, including objects of complex shapes, large surface areas, or those located in high temperature or in high places. Therefore, it is expected to be a new inspection device for aircraft, automobiles, plants, thermal and nuclear power stations, electronic parts, as well as social infrastructures such as steel bridges.

LUVI that our company developed, as seen in Fig. 1, is a device that visualizes the propagation of ultrasound as moving images by laser-scanning the surface of an object to be inspected. This is a novel device, where, if there is a defect in an object, ripples can be observed as if a spring is gushing to the water surface, and this can be easily recognized by a person even though he/she may not be an inspection specialist. $^{[1]}$

\section{Visualization principle}

The characteristic of this visualization method is the

Tsukuba Technology Co., Ltd. 1-14-11 Sengen, Tsukuba 305-0047, Japan * E-mail: saito@tsukubatech.co.jp

Original manuscript received March 3, 2017, Revisions received May 10, 2017, Accepted May 15, 2017 
measurement of ultrasonic propagation images by scanning the oscillating (sending) side, rather than the receiving side of the ultrasound. This assumes that there is reciprocity of ultrasound propagation (the receiving waveform does not change if the direction of sending/receiving is reversed). For example, as shown in Fig. 2 top, when ultrasound transmission/reception is conducted by placing an angle beam transmission transducer $\mathrm{A}$ and a normal reception transducer B with a defect (spherical groove with curvature radius of $20 \mathrm{~mm}$ and depth of $4 \mathrm{~mm}$ ) in the middle, and if the transmission/reception properties of the two transducers are the same, the waveform, where the signal is sent to A from an ultrasound pulsar and received at $\mathrm{B}$, and the waveform, where the signal is sent to B and received at A, should almost be the same as shown in Fig. 2 bottom. Therefore, as shown in Fig. 3 top, in the case of a PZT transducer, the measurement
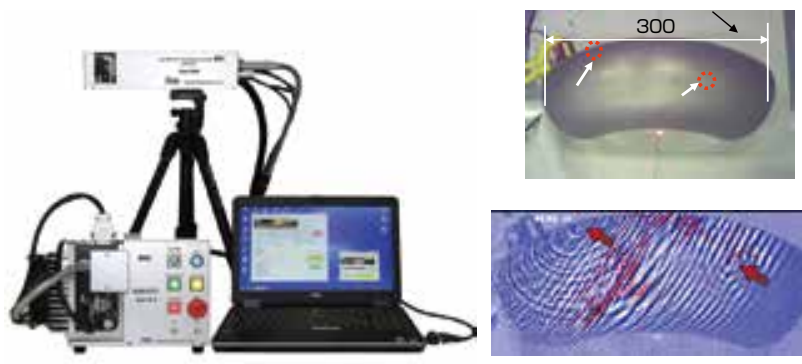

Fig. 1 Laser ultrasonic visualization inspector and an example of visualized image

(There are two simulated defects at the arrow points on the surface of the stainless elbow with thickness $6 \mathrm{~mm}$ )

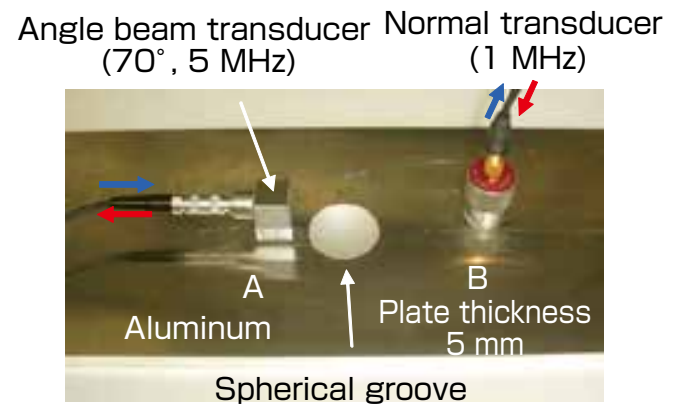

(Curvature radius $=20 \mathrm{~mm}$, depth $=4 \mathrm{~mm}$ )

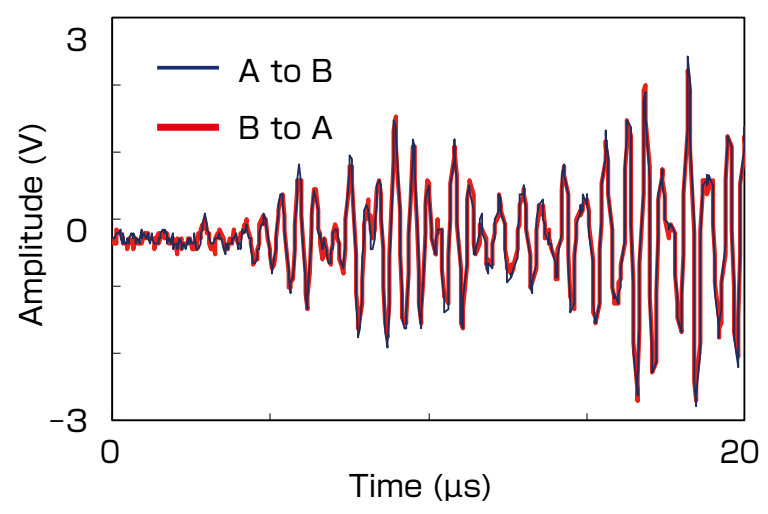

Fig. 2 Reciprocity of ultrasound propagation system can be considered equivalent even if the direction of transmission/reception are reversed regardless of the incident direction of ultrasound or the presence of a defect. Applying this to the measurement system of PZT and a laser, as shown in Fig. 3 bottom, it can be considered that the measurement system in which the thermally excited ultrasound is generated by a laser and received by a PZT transducer, and the measurement system where ultrasound is generated by a PZT transducer and received by a laser probe that has the same property as laser oscillation are equivalent. Since the measurement system where the ultrasound oscillation point is scanned with a laser and is received by a PZT transducer attached to a fixed point can be considered equivalent to the measurement system where the ultrasound produced at a PZT transducer at a fixed point is received while scanning the laser probe, it is possible to obtain moving images of ultrasound sent from a PZT transducer at a fixed point, if the receiving amplitude at each laser scanning point is displayed as images in time series by conducting brightness (color) modulation. In the conventional measurement method in which the laser probe of the receiving side is scanned, there was limitation that the laser beam had to be introduced perpendicularly to the inspection object by maintaining a constant focal length. However, in the case of laser scanning on the sending side, there is almost no limitation in the focal length or incident angle, and the laser beam can be moved freely at high speed, and this enables visualization of ultrasound traveling through three-dimensional objects.

\section{Laser ultrasonic visualizing inspector (LUVI)}

Figure 4 shows the configuration of LUVI. It has the mechanism where a laser, a galvanometer mirror, and a high-speed A/D converter are synchronized using a personal computer (PC), and a pulse laser is used for highspeed scanning in lattice form over the surface of an inspection object. Then, weak ultrasonic waves are excited by heat strain. In "contact measurement," this ultrasound propagation signal is detected by piezoelectric reception sensors (maximum eight sensors) attached to the object. In "noncontact measurement," it is detected using a laser

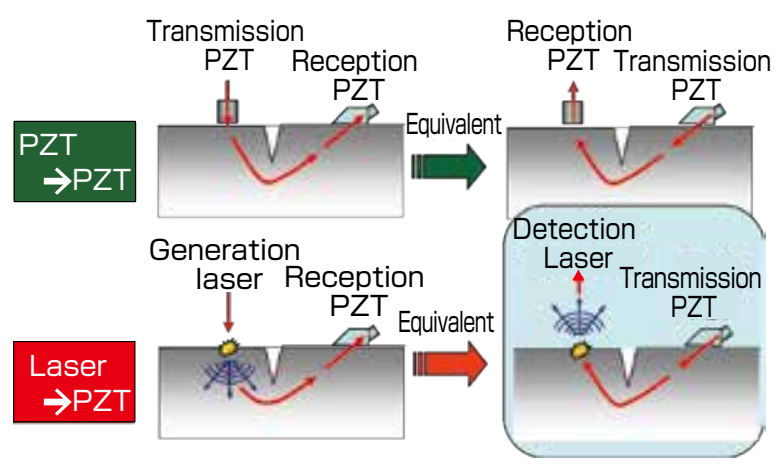

Fig. 3 Fig Comparison of reciprocities of PZT-PZT transceiver system and laser-PZT transceiver system 
Doppler vibrometer that enables noncontact reception. The signal is then amplified using an ultralow noise amplifier, and is recorded on a PC hard disk using a high-speed A/ D converter. By reconstructing the multiple ultrasound propagation signals that travel from the laser scanning point to the reception sensors by the reciprocity theorem of ultrasound propagation, visualization of ultrasound generated from the reception sensor as moving images is made possible.

\section{Types of LUVI}

As shown in Fig. 5, LUVI can be used for "contact measurement" where a reception sensor comes in contact, and for "noncontact measurement" where the laser probe is used.

Here, the characteristics of LUVI are listed.

1. It is easy to understand by non-experts because moving

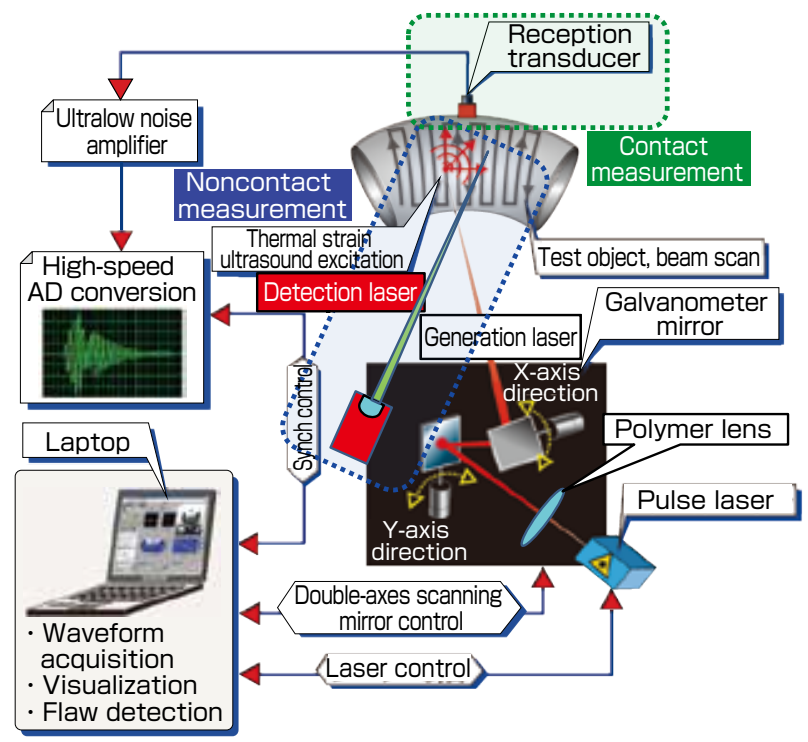

Fig. 4 Configuration of the laser ultrasonic visualization inspector (LUVI)

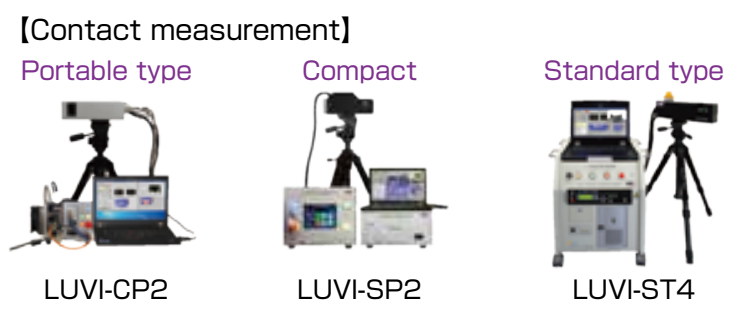

[Noncontact measurement]

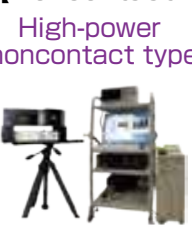

LUVI-LLN

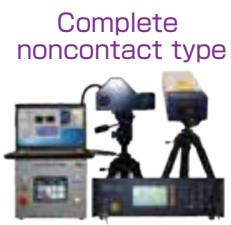

LUVI-LL2

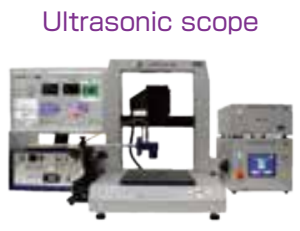

LUVI-SC 1
Fig. 5 Contact measurement and noncontact measurement LUVI images are displayed.

2. Complexly shaped objects (curved or uneven surfaces) can be inspected since it is noncontact scanning.

3. A wide range can be quickly inspected since high-speed scanning is done by mirrors.

4. It is effective in inspection of dangerous places (radioactive, high temperature, or high places) since it is noncontact inspection.

5. Web camera images can be superimposed and displayed on the moving images.

6. The abnormal area that is shown on the measurement image can be marked by a guide beam on the surface, and the location of defects can be checked in real time.

\section{Examples of application to nondestructive inspection}

\subsection{Inspection of welded parts (T-shaped welded joint)}

Next, as a case study of application of LUVI to welded parts, an example of high-speed imaging at laser scanning rate of 5,000 points/sec is presented. ${ }^{[2]}$

Figure 6 shows an image of a T-shaped welded joint (SS400 material) with width of $100 \mathrm{~mm}$. This was measured using LUVI under the following measurement conditions:

(1) Scanning rate of $1,000 \mathrm{~Hz}$; scanning pitch of $0.8 \mathrm{~mm}$

(2) Scanning rate of $5,000 \mathrm{~Hz}$; scanning pitch of $0.8 \mathrm{~mm}$

(3) Scanning rate of $5,000 \mathrm{~Hz}$; scanning pitch of $1.5 \mathrm{~mm}$ In practice, a pulse laser of wavelength of $1064 \mathrm{~nm}$ scanned the T-shaped welded part with a simulated crack, signals were detected, measurement images were analyzed, and internal flaw echoes were visualized on the spot. The results are shown in Fig. 7.

Since the welded part itself is a large defect, many false echoes are generated. Therefore, it is difficult to identify defect echoes, but the identification becomes easier if ultrasound propagation is visualized.

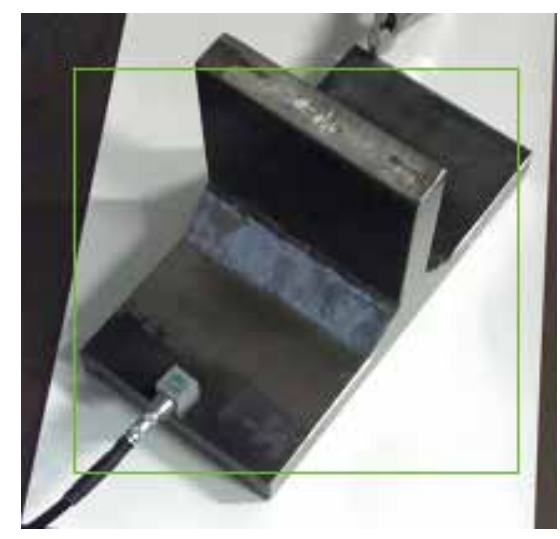

Fig. 6 T-shaped welded joint (defect in welded corner part) 
The following results were obtained under the following conditions:

(1) Scanning rate of $1,000 \mathrm{~Hz}$ and scanning pitch of 0.8 $\mathrm{mm}$, scanning time was $40 \mathrm{sec}$;

(2) Scanning rate of $5,000 \mathrm{~Hz}$ and scanning pitch of 0.8 $\mathrm{mm}$, scanning time was $3 \mathrm{sec}$; and

(3) Scanning rate of $5,000 \mathrm{~Hz}$ and scanning pitch $1.5 \mathrm{~mm}$, scanning time was $2 \mathrm{sec}$.

From the results, the following was observed:

(1) When scanning rate was $1,000 \mathrm{~Hz}$ and scanning pitch was $0.8 \mathrm{~mm}$, scanning time was $40 \mathrm{sec}$, but

(3) At scanning rate of $5,000 \mathrm{~Hz}$ and scanning pitch of 1.5 $\mathrm{mm}$, scanning time was $2 \mathrm{sec}$.

Looking at Fig. 7, the internal flaw echo is clearly detected even when the scanning time is 2 seconds in (3). Therefore, quick inspection was achieved at a short time of $2 \mathrm{sec}$, even

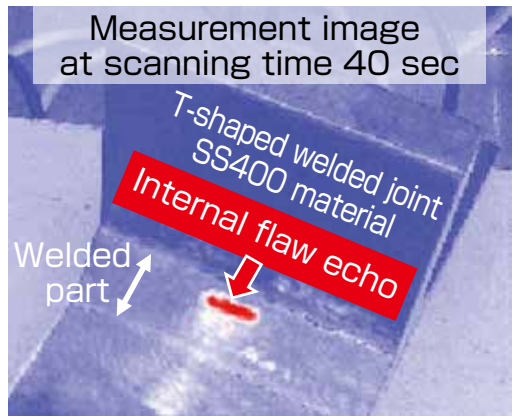

(1) Scanning rate $1,000 \mathrm{~Hz}$; scanning pitch $0.8 \mathrm{~mm}$

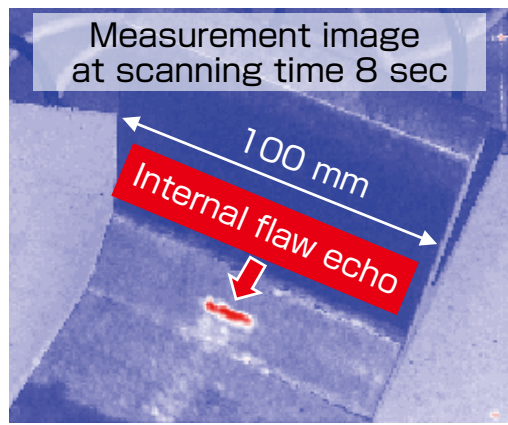

(2) Scanning rate $5,000 \mathrm{~Hz}$; scanning pitch $0.8 \mathrm{~mm}$

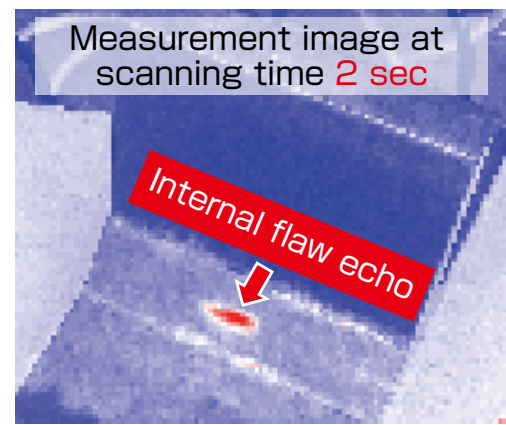

(3) Scanning rate $5,000 \mathrm{~Hz}$; scanning pitch $1.5 \mathrm{~mm}$

Fig. 7 High-speed imaging of ultrasound propagation at the welded part that is difficult to identify at laser scanning rate of 5,000 points $/ \mathrm{sec}^{[3]}$

\subsection{CFRP inspection (aircraft fan blade)}

Figure 9 is an ultrasonic propagation image of an aircraft fan blade (about $1.5 \mathrm{~m}$ in length) made of carbon fiber reinforced plastic (CFRP). An ultrasonic sensor was attached to the backside of the fan blade, and a pulse laser scanned the blade surface at a pitch of $3 \mathrm{~mm}$ from a distance of 1.5 $\mathrm{m}$. The measurement time was $50 \mathrm{sec}$ (scanning rate of $2,000 \mathrm{~Hz}$ ). Since the decay of ultrasound is great in CFRP, a vertical sensor of low frequency $(100 \mathrm{kHz})$ was used as the ultrasound sensor. Although there was no significant defect in this inspection object, it was possible to measure ultrasound that propagated throughout the surface of the fan blade using one sensor. Such CFRP inspection is being applied to automobiles as well as aircraft.

\subsection{Noncontact measurement (insulator)}

The above-mentioned results were for cases where a PZT reception transducer was used in contact measurement, and the following are examples of visualization using a noncontact laser probe.

Since there is danger of electrocution with a high-voltage insulator, a reception transducer cannot be attached directly to an insulator, and there is a need for inspection by noncontact measurement. Therefore, using an insulator with

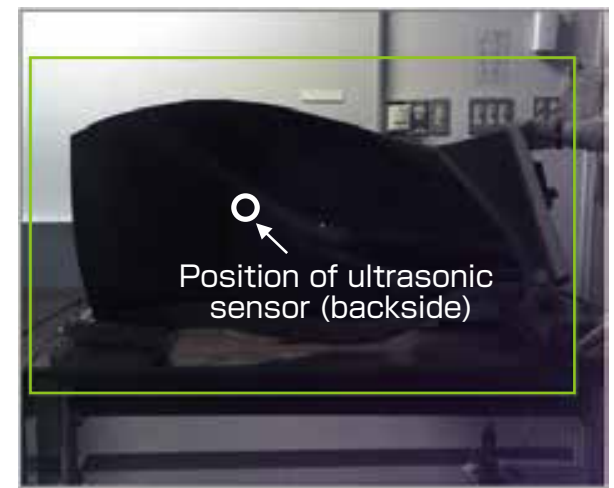

Fig. 8 CFRP aircraft fan blade

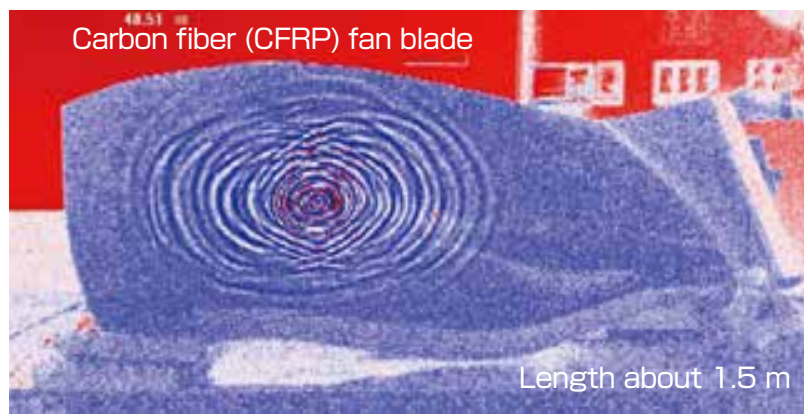

Fig. 9 Ultrasound propagation image of the CFRP aircraft fan blade 
a slit flaw as shown in Fig. 10 right, noncontact measurement of a slit flaw was attempted as shown in Fig. 10 left.

The slit flaw echo measurement is shown in Fig. 11. Since detection sensitivity decreases in noncontact measurement compared to contact measurement, one spot was irradiated five times and the average was taken. Echoes from the slit flaw and traveling waves of ultrasound that spread from the irradiation point of the laser probe can be observed.

\subsection{Inspection of social infrastructures (steel bridges)}

The application of nondestructive inspection to industrial infrastructures was discussed above, but the urgent issue for Japan is the inspection of aging social infrastructures. We are trying to develop defect inspection technology by a noncontact and nondestructive method, particularly for effective and remote detection of cracks that occur in steel bridges, using laser ultrasound, and are trying to save manpower and to simplify inspection work as well as to increase inspection accuracy.

An actual steel bridge inspection is shown in Fig. 12. As shown in Fig. 12 right, an inspection device (LUVI) was placed on an inspection vehicle, the laser scanned the welded part of the stiffener of the main girder upper flange, and a contact sensor was attached. Then, visualization measurement of fatigue cracks using ultrasonic echoes was attempted.

Figure 13 right is the crack echo observed by measuring the frame part shown in Fig. 13 left. Here, it is important to note that it is possible to measure the propagation of ultrasound as a moving image, even when laser scanning is done on the inspection surface of the steel bridge that is covered by a coating film. If there is a crack, the ripple wave echoes can be seen in the measurement image, and the presence of the crack and its size under the coating film can be determined.

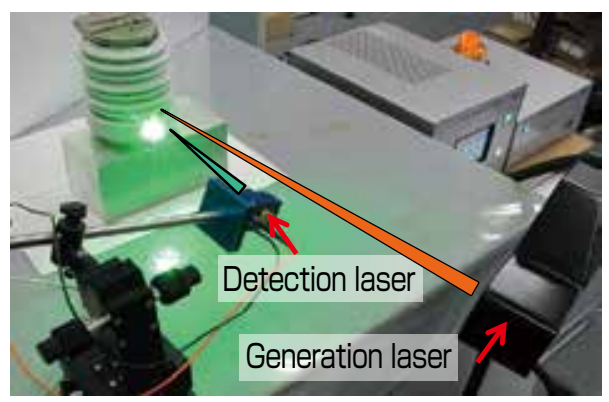

Fig. 10 Insulator with cracks

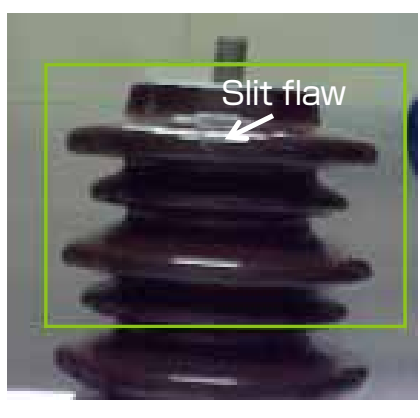

Fig. 11 Noncontact measurement image of the insulator with cracks
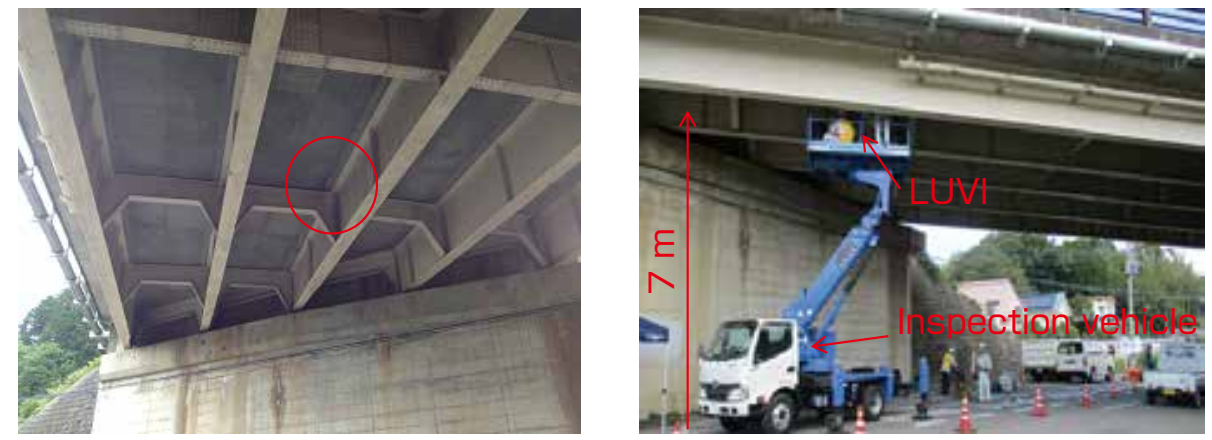

Fig. 12 Scene of fatigue crack inspection in the welded part of a steel bridge
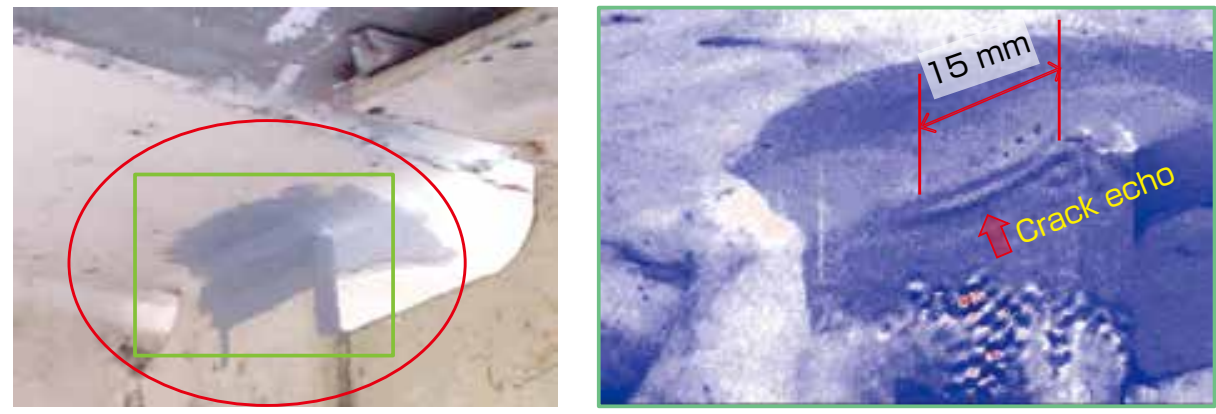

Fig. 13 Fatigue crack echo of the welded part of steel bridge 
Since this is noncontact scanning by a laser, the echo can be observed quickly and remotely for a wide inspection surface or complex shaped parts such as corner welded parts.

\section{Future of laser ultrasound technology}

LUVI is gaining attention as an innovative technology that allows inspection that was conventionally considered difficult, including the following: the inspection of curved objects such as plant pipes, aircraft engine blades, or rocket boosters; the inspection of narrow or uneven parts such as automobile engine blocks or transmission cases; the inspection in radioactive environment such as nuclear power plants; the inspection under high temperature such as during welding; the inspection in high places such as tunnels or steel bridges; and the inspection of CFRP materials in aircraft and automobiles. It is being introduced to various places now.

\section{Dry-cell-operated compact X-ray inspector and its application to nondestructive inspection}

Using a carbon nanostructure cold cathode X-ray tube $\mathrm{e}^{[4]}$ that was researched at AIST, we developed ${ }^{[5]}$ and formed into a product ${ }^{[6][7]}$ an X-ray inspector with output of $60 \mathrm{kV}, 100 \mathrm{kV}$, $120 \mathrm{kV}$, and $150 \mathrm{kV}$. Particularly, a palm-sized compact X-ray inspector that can conduct practical inspection with one AA battery is a type that has never been seen before. This enables on-site inspection by allowing the X-ray inspectors in places where formerly such a device could not be taken. Here, specific application of these X-ray inspectors to various fields will be described.

\section{Cold cathode X-ray tube that can be operated with a dry cell}

Carbon nanostructure used in our compact X-ray inspector and its cold cathode electron source are shown in Fig. 14.

As shown in this photograph, the carbon nanostructure cold cathode electron source is in the shape of a conifer tree. It is thick at the substrate side, and the resistance to field force is strong. This is because when the substrate side is thick, just

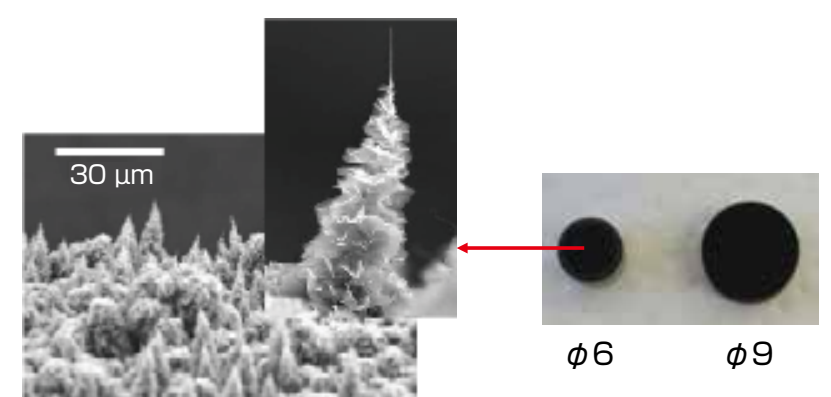

Fig. 14 Carbon nanostructure (left) and cold cathode electron source (right)
Table 1. Comparison of the Hot cathode $x$-ray tube and the cold cathode X-ray tube

\begin{tabular}{|c|c|}
\hline Hot cathode X-ray tube & Cold cathode X-ray tube \\
\hline & \\
\hline $\begin{array}{l}\text { (1) Hot electrons emitted } \\
\text { from filament } \\
\text { (2) Preheating of filament } \\
\text { and standby power } \\
\text { necessary } \\
\text { (3) Must wait until the } \\
\text { filament temperature } \\
\text { reaches a certain level } \\
\text { (4) Needs preheating and } \\
\text { running cost is high } \\
\text { (5) Large and heavy power } \\
\text { source unit, cumbersome } \\
\text { handling } \\
\text { (6) Filament lifespan is a } \\
\text { problem }\end{array}$ & $\begin{array}{l}\text { (1) Field emission by cold } \\
\text { cathode carbon } \\
\text { nanostructure } \\
\text { (2) Preheating of filament } \\
\text { and standby power are } \\
\text { not necessary } \\
\text { (3) Pulse action allows } \\
\text { instant start-up of } \\
\text { X-ray tube } \\
\text { (4) Operable with dry cells, } \\
\text { running cost is inexpensive } \\
\text { (5) Compact/lightweight can } \\
\text { be achieved for entire } \\
\text { X-ray generator } \\
\text { (6) Long lifespan of } 10 \text { million } \\
\text { shots due to carbon } \\
\text { nanostructure }\end{array}$ \\
\hline
\end{tabular}

like a tree, even if it gradually erodes at the top, the thickness on the substrate side allows the structure to be less affected by electric fields and is resilient just like the thick trunk of a tree. Therefore, it is characterized by having a long lifespan compared to the filaments and heaters of a Hot cathode electron source that is used commonly in X-ray tubes. A cold cathode X-ray tube equipped with a carbon nanostructure cold cathode electron source is shown in Fig. 15.

The cold cathode X-ray tube shown in Fig. 15 has the length of about two or three AA batteries. Many electrons are emitted due to a field emission phenomenon from the tip of the carbon nanostructure cold cathode electron source shown in Fig. 14. Since there is no heater or filament in this X-ray tube, preheating and aging are unnecessary, and X-rays can be irradiated immediately. Since it consumes power only during X-ray generation, it is energy saving and can be operated with one AA battery.

Table 1 shows a comparison with a Hot cathode X-ray tube,

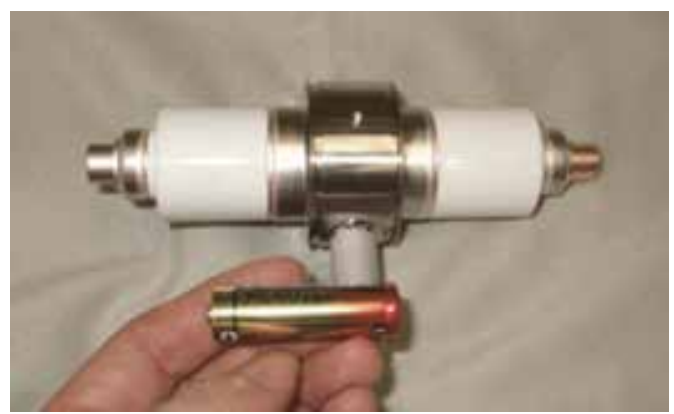

Fig. 15 Cold cathode X-ray tube equipped with carbon nanostructure cold cathode electron source 
Fig. 16 shows the internal structure of a Hot cathode X-ray tube, and Fig. 17 shows the internal structure of a cold cathode X-ray tube.

A Hot cathode electron source needs preheating and standby voltage to emit Hot electrons, and this requires corresponding circuits that make the whole device large and heavy. In comparison, a cold cathode electron source emits field electrons as soon as voltage is applied, can provide instant irradiation, and does not require preheating or standby voltage. Therefore, the device has the advantage of being energy-saving, small, and lightweight.

\section{AA-battery-operated compact X-ray inspector}

Figure 18 shows a dry-cell-operated compact X-ray inspector that is palm-sized, which was realized by the installation of the above-mentioned cold cathode X-ray tube. This device boosts the voltage of one AA battery $(1.5 \mathrm{~V})$ several stages through its originally developed booster circuit, and boosts it 40,000 times up to tube voltage $60 \mathrm{kV}$. This allows the irradiation of X-rays at tube voltage of $60 \mathrm{kV}$ with one AA battery, from a device with thickness of $70 \mathrm{~mm}$ or less and weight of $1.8 \mathrm{~kg}$.

This compact and lightweight device is capable of irradiating about 100 shots of pulse X-rays at $50 \mathrm{~ms}$ per shot with

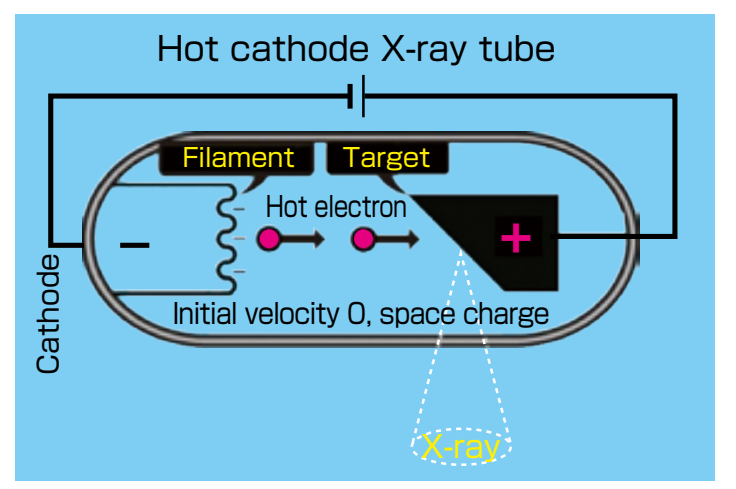

Fig. 16 Internal structure of the Hot cathode X-ray tube

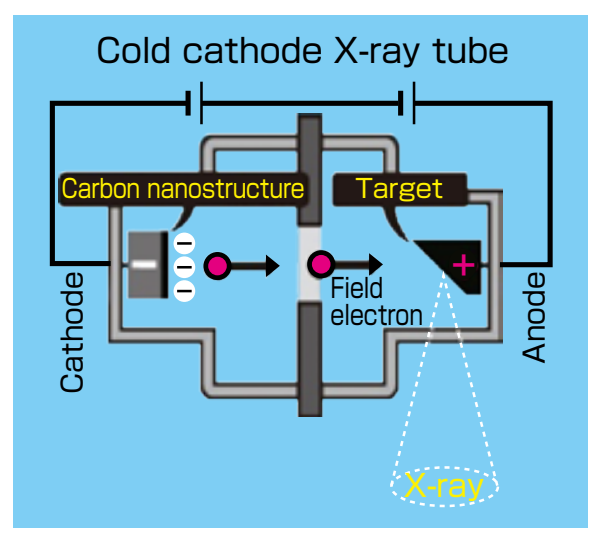

Fig. 17 Internal structure of the cold cathode X-ray tube one AA battery. When used as an actual nondestructive inspector, it will be equipped with two $7.2 \mathrm{~V}$ small lithium ion batteries of width $2 \mathrm{~cm} \times$ length $3 \mathrm{~cm} \times$ thickness $1 \mathrm{~cm}$. The booster factor is optimized, and the number of pulses that can be irradiated is about 5,000 shots.

The effective focal size of the X-rays is $1 \mathrm{~mm}$, and this is small compared to the effective focal size of $3 \mathrm{~mm}$ for X-ray inspectors equipped with a general Hot filament X-ray tube. Therefore, a high-resolution image can be obtained even when imaging is done at a short distance from an object.

\section{Compact X-ray inspector for pipes}

\subsection{Compact $X$-ray source}

At industrial plant sites, the space between pipes is about 10 $\mathrm{cm}$, and therefore, it was difficult to insert a conventional $\mathrm{X}$-ray source device into this space. We set the thickness of the X-ray source to $7 \mathrm{~cm}$, and set out to fabricate a device that can irradiate $\mathrm{X}$-rays from the gap between the pipes. ${ }^{\left[{ }^{[3}\right.}$

Figure 19 shows a compact X-ray source that we developed with thickness of $7 \mathrm{~cm}$. This X-ray source uses the abovementioned cold cathode X-ray tube as its X-ray tube, and has tube voltage of $150 \mathrm{kV}$ and maximum tube current of $2 \mathrm{~mA}$, though it is compact and lightweight at thickness of

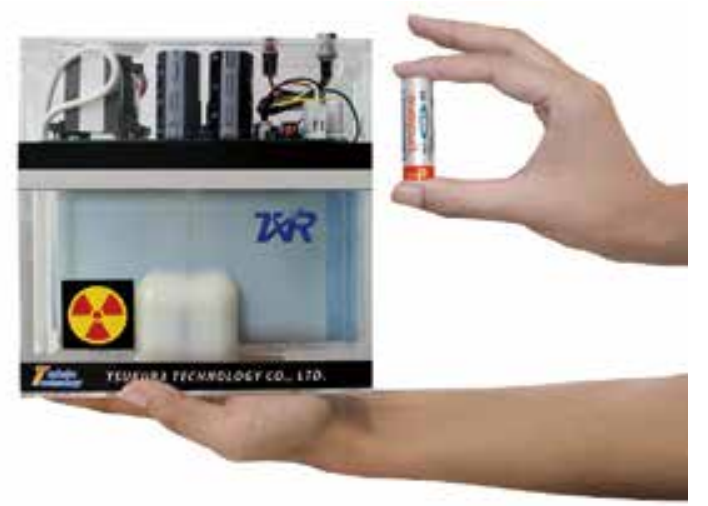

Fig. 18 Dry-cell-operated compact X-ray inspector that fits on a palm

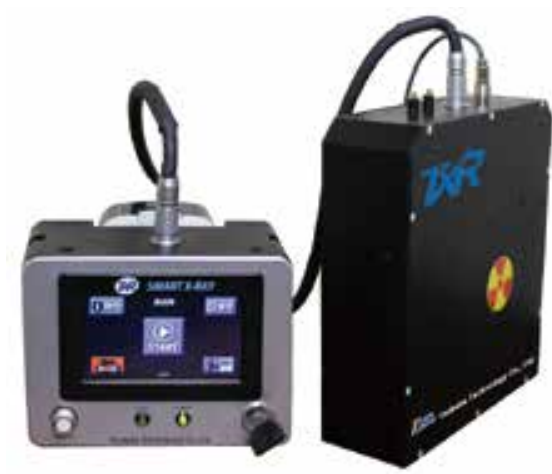

Fig. 19 Compact X-ray source 
$7 \mathrm{~cm}$ and weight of $6 \mathrm{~kg}$. It employs a controller to enable $\mathrm{X}$-ray inspection of tubes in high or narrow space from a distant place in the plant. The X-ray can be irradiated from a distance of $20 \mathrm{~m}$ to obtain a detector image. This allows safe and efficient inspection by workers. Since it is battery operated, it does not require a $100 \mathrm{~V}$ power source, and it is suitable for use on site.

\subsection{Developed device}

Figure 20 shows our developed compact X-ray inspector for pipes. This device has a controller that allows irradiation of X-rays from a distance of $20 \mathrm{~m}$. It consists of a compact X-ray source of thickness of $7 \mathrm{~cm}$, a thin detector of width of $5 \mathrm{~cm}$, and a personal computer for control and display. This device is compact, lightweight, portable, and mobile, and the inspection can be conducted by placing it between pipes wrapped with insulating material.

To inspect pipes using this device, we newly developed a cold cathode X-ray tube and a booster circuit, and achieved output of $150 \mathrm{kV}$. As the tube voltage reached $150 \mathrm{kV}$, we used our original solid mold as the insulating mold to ensure portability. To keep the thickness of the X-ray source to $7 \mathrm{~cm}$, the high-voltage circuit was downsized and highly integrated, and was enclosed in the body. Using a controller, photography conditions such as tube voltage, tube current, pulse width, and pulse frequency can be changed depending on the diameter and thickness of the pipes, and X-rays can be irradiated from a place $20 \mathrm{~m}$ away from the X-ray source. From the control/display PC, the operator can irradiate $\mathrm{X}$-rays by pushing the X-ray irradiation button on the screen, data from the detector can be read, image processing can be done, and photographed images can be displayed in real time. The displayed images can be adjusted for brightness and contrast, and zoom and size can also be displayed.

\subsection{Thickness reduction inspection of pipes}

The X-ray source has thickness of $7 \mathrm{~cm}$ and weight of $6 \mathrm{~kg}$. It is placed between pipes, is battery operated, and irradiates $\mathrm{X}$-rays in a horizontal direction. It can irradiate pulse X-rays of pulse width of $30-200 \mathrm{~ms}$ at tube voltage of $100-150 \mathrm{kV}$, using a controller from a $20 \mathrm{~m}$ distance.

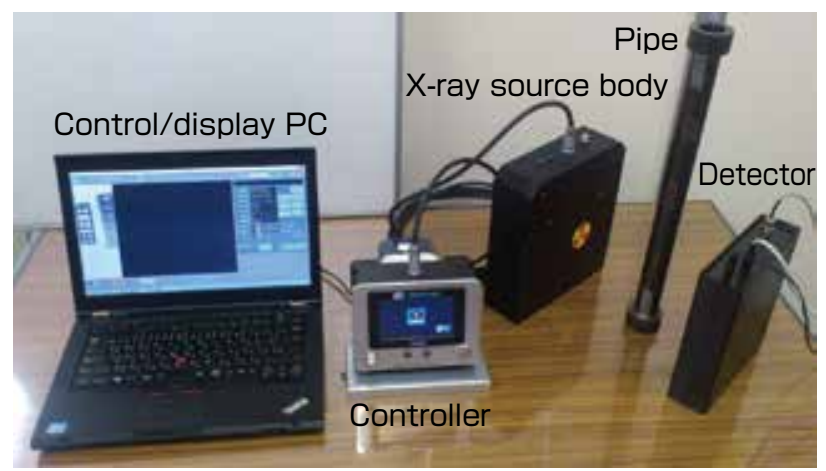

Fig. 20 Compact X-ray inspector for pipes
The effective focal size is $1 \mathrm{~mm}$, and a high-resolution image can be obtained even if X-rays are irradiated right near the pipes that are wrapped with insulating material. Figure 21 shows an example of a size display of an object that simulates a thickness reduced pipe. The image shows an eroded end of a simulated thickness reduced pipe. The external diameter of this pipe was $34 \mathrm{~mm}$, the thickness was $6.8 \mathrm{~mm}$, and the thinning depth of the protruding part was $1.8 \mathrm{~mm}$. The conditions for photography were tube voltage of $140 \mathrm{kV}$, tube current of $1 \mathrm{~mA}$, pulse width of $100 \mathrm{~ms}$, and 1 pulse.

The comparison of the displayed thinning depth of the protruding part and the actual measurement values was as follows:

Actual value: Protrusion length of $21.0 \mathrm{~mm}$, protrusion depth of $1.8 \mathrm{~mm}$

Displayed value: Protrusion length of $21.09 \mathrm{~mm}$, protrusion depth of $1.83 \mathrm{~mm}$

From these values, the differences between the actual value and the displayed value were $0.09 \mathrm{~mm}$ for protrusion length and $0.03 \mathrm{~mm}$ for protrusion depth, and the possibility of thickness loss measurement in piping inspection was confirmed.

\section{Compact X-ray inspector for power lines}

12.1 Current situation and issues in power line inspection With the 2020 Tokyo Olympics on the horizon, the maintenance of social and industrial infrastructures has become an urgent issue for Japan. Among such infrastructure maintenance, power lines and their inspection are extremely important for ensuring power supply.

However, there was no effective inspection method for power lines. For the inspection of high-voltage power lines, the inspector must climb up to the lines and visually check them. This method involves danger of work in high places, moreover, the power must be stopped, and it is difficult to conduct safe and efficient inspection.

Therefore, to solve this problem, we developed a compact $\mathrm{X}$-ray inspector that combines a dry-cell-operated compact $\mathrm{X}$-ray source with the above-mentioned cold cathode X-ray tube and a flat panel detector (FPD), ${ }^{\text {Term }}$ and are working on

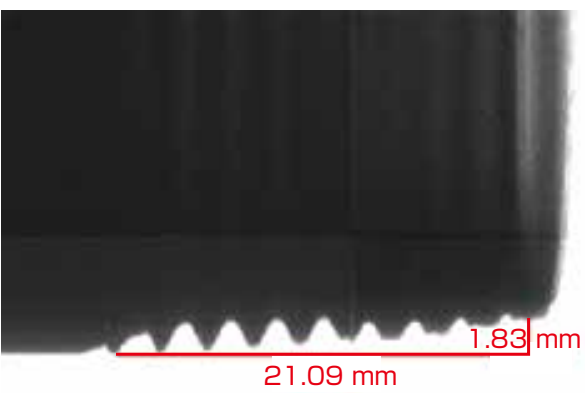

Fig. 21 Example of display of pipe size 
promoting its practical use.

\subsection{Compact $X$-ray inspector for power lines}

The compact X-ray inspector for power lines with a cold cathode X-ray tube is shown in Fig. 22.

For this device, an X-ray tube and a booster circuit were newly developed to obtain $70-120 \mathrm{kV}$ that is necessary for power line inspection, by increasing the tube voltage of the $60 \mathrm{kV}$ compact X-ray inspector that was described earlier.

This device is comprised of an X-ray inspector part and a control/display PC, and the former is comprised of a compact $\mathrm{X}$-ray source and FPD. In actual inspection, the power line to be inspected is placed between the compact X-ray source and FPD of the X-ray inspector part, the lid is closed so the power line is held and fixed, and X-rays are irradiated to conduct inspection.

The photography condition can be set using the control panel of the X-ray inspector unit, at tube voltage of $70-120 \mathrm{kV}$, pulse width of 20-100 ms, and pulse frequency of 1-100. Of course, this setting can also be done from the control/display PC.

During actual inspection, X-rays are irradiated by operation on the PC screen, the transmission image is detected by FPD, the signals are transferred to the PC through LAN cables, and the transmission image is displayed on the PC screen using image display software.
Here, the device shown in Fig. 22 is used for power lines or any objects that are in wire form, but for objects of other shapes, the main body without a hole, as shown in Fig. 23, can be used for research in combination with an appropriate X-ray source. By switching the frame body, various objects can be inspected, and this allows expansion of the range of inspection. In fact, objects up to a size of width $260 \mathrm{~mm} \times$ depth $80 \mathrm{~mm} \times$ height $170 \mathrm{~mm}$ can be placed in the frame body. The frame body size of this device is $270 \times 270 \times 180$ $\mathrm{mm}$, the weight is $20 \mathrm{~kg}$, and it can be transported by one person. ${ }^{[9]}$

The frame body of the X-ray inspector part has been lead insulated to keep the leakage dose rate of X-rays to $0.6 \mu \mathrm{Sv} /$ $\mathrm{h}$ or less, and a wide range of inspection for power lines and other objects can be done at laboratories and offices by a person without qualification for operation chief of work with $\mathrm{X}$-rays. This device is compact, lightweight, and portable so it can be taken to the site, and allows quick inspection of power lines or other objects.

\subsection{Image of power line inspection}

$\mathrm{X}$-rays were irradiated at tube voltage $100 \mathrm{kV}, 50 \mathrm{~ms}$, and 1 pulse using this device, and the image of a power line photographed under this condition is shown in Fig. 24.

The transmission image of Fig. 24 shows parts of copper wire and aluminum strand wire lines well and clearly. This software can conduct various image processing, enlargement and reduction at real time on screen, display histograms, and

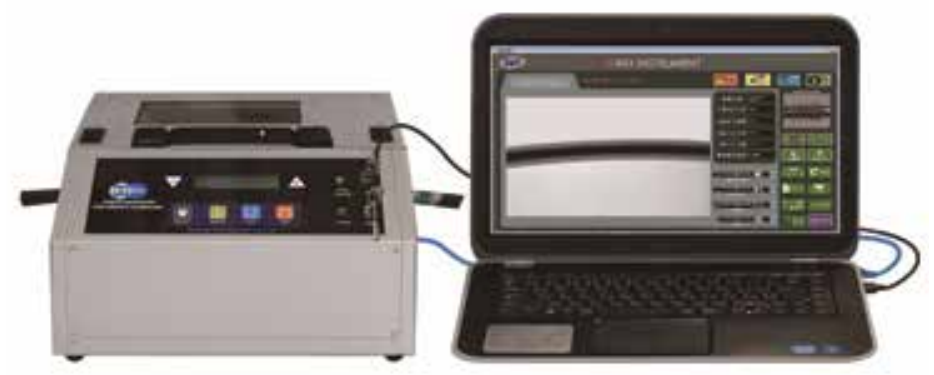

Fig. 22 Compact X-ray inspector for power lines

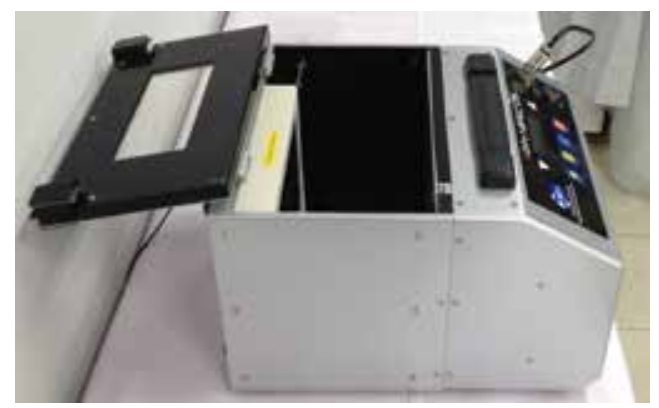

Fig. 23 Compact X-ray inspector for research

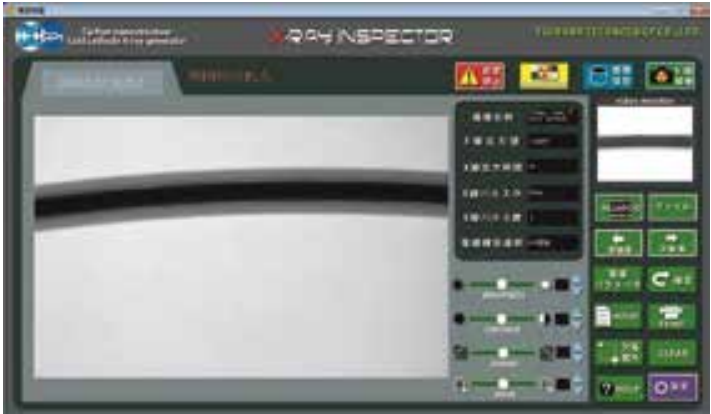

Fig. 24 Image of a power line 
adjust brightness and contrast.

The FPD of this device is capable of digital output and can immediately display the photography results, and an object can be re-photographed several times at different conditions. Therefore, the object can be inspected at optimal photo conditions, and the defect parts can be identified and the degree of corrosion can be quantified easily. The detection area of this FPD is $10.2 \times 15.3 \mathrm{~cm}$ and pixel pitch is $99 \mu \mathrm{m}$, and these figures lie in the practical range of an inspector for power lines with thickness of about $10-40 \mathrm{~mm}$.

\subsection{Self-propelled compact X-ray inspector for power lines}

In a project of the Kanto Bureau of Economy, Trade and Industry, we developed a self-propelled compact X-ray inspector for power lines as shown in Fig. 25.

This self-propelled compact X-ray inspector for power lines has three sets of compact X-ray sources and X-ray detection panels arranged in the top and bottom parts opposed to each other, as shown in the diagram of the internal structure in Fig. 25. This allows photography of the entire circumference of power lines at once. The developed device underwent self-propelled trials targeting simulated power lines of an electrical wire manufacturer, and good results were obtained. In the future, tests will be done on real power lines. We hope to make contribution to the maintenance of power infrastructure through such power line inspection. We plan to widen application to those other than power companies, such as inspection of ropes of suspended bridges or the inspection of wires of elevators.

\section{Conclusion}

In this report, we discussed the development and application of the laser ultrasonic visualization inspector and the drycell-operated compact X-ray inspector. The LUVI is starting to be used in screening and inspection of social and industrial infrastructures. Currently, to enhance its diffusion, we are
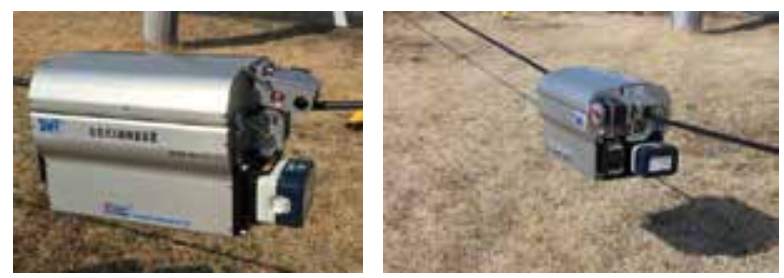

Scene of self-propulsion test on power line

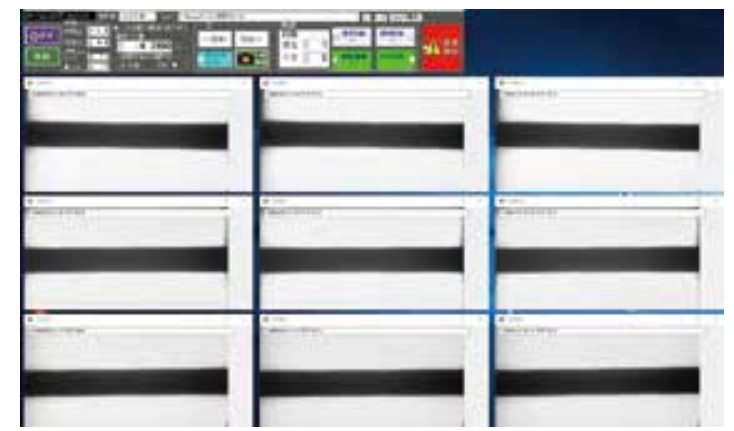

Three-direction photo image of power line

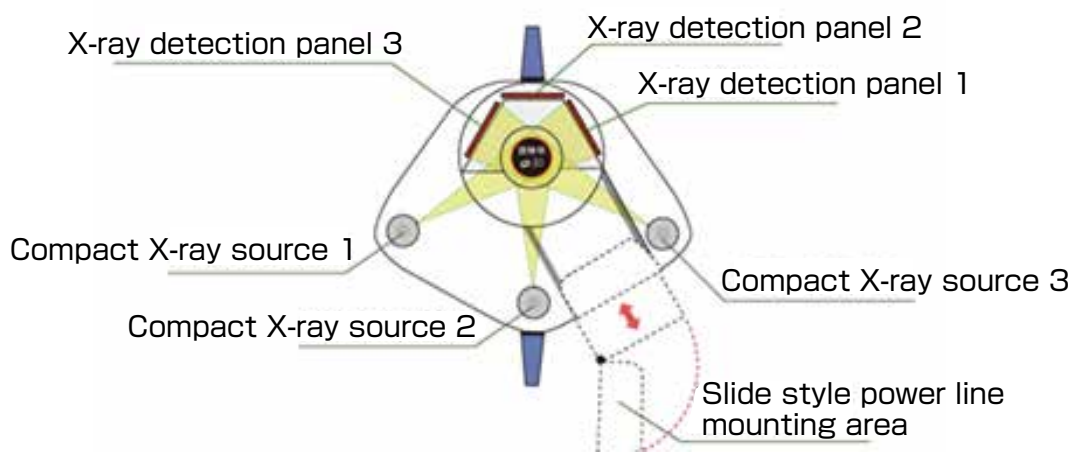

Arrangement within the device

Fig. 25 Self-propelled compact X-ray inspector for power lines 
working on the standardization of this technology through the Japan Standards Association. We are also working on the domestic production of laser light sources.

For dry-cell-operated compact X-ray inspectors, other than the nondestructive inspection described here, ${ }^{[10]}$ we are developing a portable chest X-ray photography device for home medical care ${ }^{[11]}$ and a device that can display tomosynthesis imagery by conducting X-ray photography from four directions using an irradiation head equipped with four X-ray sources. Through such efforts, we are working to diffuse the technologies of AIST from Tsukuba to the world.

\section{Acknowledgements}

For this development, we received enormous cooperation from Hiroshi Tsuda, Principal Research Manager; Nobuyuki Toyama, Group Leader; and Ryoichi Suzuki, Prime Senior Researcher of AIST. We express our deep gratitude.

For the development of LUVI, part of the research was conducted through grants from: "Development of an innovative laser ultrasonic inspector that can conduct noncontact inspection on site for internal defects of electronic parts and devices," No. 23130803009, Strategic Core Technology Advancement Program (Supporting Industry Program), Kanto Bureau of Economy, Trade and Industry; "Development for practical application for a laser ultrasonic visualization inspector for on-site use," No. 0426001 (FY 2013), Innovation Commercialization Venture Support Project, New Energy and Industrial Technology Development Organization (NEDO); and "Development of diagnostic technology for steel bridge deterioration using laser ultrasonic visualization inspection technology," No. B020, "SIP Infrastructure Maintenance, Renewal, and Management Technology" (managed by JST), Council for Science Technology Policy, Cabinet Office.

The development of the dry-cell-operated compact X-ray inspector was conducted through grants from the following: "Small, lightweight, and portable X-ray inspector," No. AS2416903K, Adaptable and Seamless Technology Transfer Program through Target-Driven R\&D (A-STEP), Japan Science and Technology Agency; "Development of compact, selfpropelled X-ray inspector for detecting defects in power lines," No. 2630811040, Strategic Core Technology Advancement Program (Supporting Industry Program), Kanto Bureau of Economy, Trade and Industry; and "Development and commercialization of a portable 3D display X-ray photography device," No. 26-123, Development of Medical Devices through Collaboration between Medicine and Industry, Japan Agency for Medical Research and Development and Ministry of Economy, Trade and Industry.

\section{Terminologies}

Term Flat panel detector (FPD): Planar X-ray detector used in X-ray photo-imaging device.

\section{References}

[1] J. Takatsubo: Generation laser scanning method for visualizing ultrasonic waves propagating on 3-D objects, Journal of the Japanese Society for Non-Destructive Inspection, 57 (4), 162-168 (2008) (in Japanese).

[2] N. Saito, J. Takatsubo, B. Wang, XJ. Liu, S. Suzuki and XD. Wang: Visualization of weld defects echo by laser ultrasonic visualization technology, Kensa Gijutsu, 20 (10), 67-69 (2015) (in Japanese).

[3] N. Saito, J. Takatsubo, B. Wang, XJ. Liu and S. Suzuki: Principle and application of laser ultrasonic visualizing inspector, Kensa Gijutsu, 22 (2), 16-20 (2017) (in Japanese).

[4] R. Suzuki: Development of battery-operated portable high-energy X-ray sources-Innovation in X-ray nondestructive-evaluation, Synthesiology, 2 (3), 237-243 (2009) (in Japanese) [Synthesiology English edition, 2 (3), 221-228 (2009)].

[5] N. Saito, XD. Wang, K. Matsuoka and B. Wang: Tansan kandenchi kudo $\mathrm{x}$-sen sochi ni yoru densen'yo kogata $\mathrm{x}$-sen kensa sochi (Compact X-ray inspector for power line using AA-battery-operated X-ray device), Eizojoho Industrial, 46 (2), 41-46 (2014) (in Japanese).

[6] N. Saito, B. Wang, XD. Wang, K. Adachi and DX. Yu: Tansan kandenchi kudo x-sen sochi no jitsuyoka (Practical application of AA-battery-operated compact X-ray device)), Eizojoho Industrial, 47 (2), 13-17 (2015) (in Japanese).

[7] N. Saito, B. Wang, XD. Wang, S. Suzuki and XJ. Liu: Compact X-ray inspection system using a power saving $\mathrm{X}$-ray tube which can be driven by dry batteries and its application, Journal of the Japanese Society for NonDestructive Inspection, 64 (5), 210-215 (2015) (in Japanese).

[8] N. Saito, B. Wang, XJ. Liu and S. Suzuki: Kogata X-sen kensa sochi (Compact X-ray inspector), Kensa Gijutsu, 21 (3), 30-33 (2016) (in Japanese).

[9] N. Saito, B. Wang, XJ. Liu and S. Suzuki: Rei-inkyoku kogata $\mathrm{X}$-sen kensa sochi no kaihatsu to oyo (Development and application of cold cathode compact X-ray inspector), Kensa Gijutsu, 21 (8), 59-62 (2016) (in Japanese).

[10] N. Saito, B. Wang, XJ. Liu and S. Suzuki: Principle and application of the battery-operated compact X-ray inspection system, Kensa Gijutsu, 22 (1), 62-66 (2017) (in Japanese).

[11] N. Saito, B. Wang, XJ. Liu and S. Suzuki: Zaitaku iryoyo kandenchi kudo portable rei-inkyoku X-sen satsuei sochi no kaihatsu (Development of dry-cell-operated portable cold cathode X-ray photography device for home medical care), Eizojoho Medical, 48 (13), 54-59 (2016) (in Japanese). 


\section{Authors}

\section{Bo WANG}

Graduated from the Department of Radar Systems, Xidian Univerity (Xian, China) in 1982. Completed the master's program at the Xidian University in 1986, then became assistant and lecturer. Studied abroad at University of Tsukuba in 1993, and engaged in research for image processing by CT and MRI. Engaged in research for $3 \mathrm{D}$ image processing and

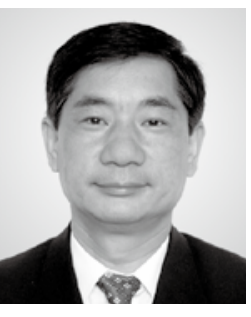
nondestructive inspection technology at the National Institute of Information and Communications Technology (NICT) and AIST in 1999. Established Tsukuba Technology Co., Ltd. in 2005, and is in charge of R\&D and general management. Received the Excellence Award, 6th Monozukuri Nippon Grand Award.

\section{Junji TAKATSUBO}

Graduated from the Nagoya Institute of Technology in 1973; and obtained Doctor of Engineering at the University of Tokyo in 1991. Engaged in research on acoustic emission, ultrasonic inspection, and laser ultrasonic visualization technology for over 30 years. From 2011, works on the development and product realization of laser ultrasonic visualization inspector and is in charge of general technology at Tsukuba Technology Co., Ltd., a venture company for technology transfer of AIST technologies. Received the Excellence Award, 6th Monozukuri Nippon Grand Award.

\section{Norio SaITo}

Completed the master's course at the Yamagata University in 1985. Engaged in the research of Mie scattering laser radar at the National Institute for Environmental Studies, and then worked on the development of high-output, highly stable YAG laser at NEC Corporation. From 2012, is in charge of general R\&D at Tsukuba Technology Co., Ltd. Received the Excellence Award, 6th Monozukuri Nippon Grand Award.

\section{Xiaojun LIU}

Graduated from the Shandong University in 1982. Studied abroad from 1992. Obtained doctorate in Management Science and Engineering, University of Tsukuba in 1999. Engaged in research for actuarial calculation and numerical simulation for 14 years at the Geospatial Information Authority of Japan, National Institute for Materials Science (NIMS),

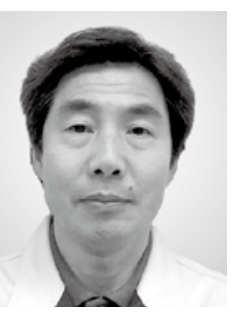
and AIST. Jointly established Tsukuba Technology Co., Ltd. in 2005, and is in charge of general management and finance. Received the Excellence Award, 6th Monozukuri Nippon Grand Award.

\section{Shuichi SuZUKI}

Graduated from Nihon University in 1992. Worked for 20 years at the division of measurement development at a measurement device company. Worked on the development of hardware and software of measurement devices. Joined Tsukuba Technology Co., Ltd. in 2012, and is in charge of product realization and manufacturing. Received the Excellence Award, 6th Monozukuri Nippon Grand Award.

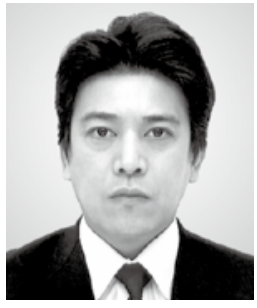

\section{Discussion with Reviewers}

\section{Overall}

Comment (Ken'ichi Fujii, AIST)

Response to aging of the social and industrial infrastructures is a major social issue, and therefore, I think the value of this report that explains the development of new inspection technology is high. This report describes two technologies, visualization technology by laser ultrasound and compact X-ray technology by carbon nanotube structure cold cathode X-rays.

Comment (Keiichi Ikegami, AIST)

This report discusses a case study in which a venture company utilizes the technological potentials of a public research institute, including laser ultrasound visualization technology and compact cold cathode X-ray source technology, to develop and commercialize two types of nondestructive inspectors, both of which are the first in the world. The practical effectiveness that is the appeal point of the products is presented through demonstration. This report is very instructive in considering the commercialization of technological potential in a synthesiological manner, and is worthy of publication in Synthesiology.

\section{Visualization technology by laser ultrasound Question \& Comment (Ken'ichi Fujii)}

You provide detailed descriptions of the social demands and the examples of application of this technology, but there are no details about the scanning method of pulse lasers. You simply mention "lattice form" in Chapter 3, and there are no technical details.

I think you should provide explanation for the technical concept, "reciprocity theorem," of ultrasound propagation. The readers will be aided in understanding the uniqueness of this technology if you provide explanation about the principles and methods for visualization of moving image information. Answer (Junji Takatsubo)

For the reciprocity theorem, we provided explanation by adding a new chapter " 3 Visualization principle."

\section{Compact X-ray technology by carbon nanotube structure cold cathode X-ray \\ Question \& Comment (Ken'ichi Fujii)}

You provide explanation on the characteristics of the carbon nanotube structure cold cathode X-ray source in Chapter 8, but I couldn't understand why it is more advantageous than the Hot cathode electron source that is used in general X-ray tubes. Particularly, can you explain why resistance against field force increases when the substrate side is thicker?

\section{Answer (Norio Saito)}

The Hot cathode electron source requires preheating and standby voltage to emit Hot electrons. More circuits become necessary, and accordingly, the device tends to become large and heavy. In contrast, the cold cathode electron source emits field electrons as soon as the voltage is applied, thus enabling instant irradiation. It does not require preheating or standby voltage, and that makes it energy saving, compact, and lightweight. Also, when the substrate side is thick, even if the tip gradually erodes due to 
the effect of electric fields, the thick substrate side is less affected and its resilience increases.

\section{Comment (Ken'ichi Fujii)}

The measurement principle has become more understandable, since you added a new chapter, Chapter 3 (Visualization principle), as well as Fig. 2 (Reciprocity of the ultrasound propagation) and Fig. 3 (Comparison between the reciprocities of PZT-PZT transceiver system and laser-PZT transceiver system). Also, the advantages became clear, as you added the characteristic when the carbon nanotube structure is used in the cold cathode source. I expect that your device will contribute further in dealing with the aging of social and industrial infrastructures, through further downsizing and weight reduction.

\section{Scenario}

\section{Question \& Comment (Keiichi Ikegami)}

For the "scenario" that is considered highly important in Synthesiology, you mention that your development is "based on the compact X-ray technology using carbon nanostructure cold cathode X-rays and the world's first visualization technology by laser ultrasound among the nondestructive inspection technologies developed at AIST." What are your thoughts and background that turned you to these two particular technologies?

\section{Answer (Bo Wang, Junji Takatsubo, and Norio Saito)}

Laser ultrasound has excellent properties [(1) it can be easily used by an untrained person since it is displayed as moving images, (2) it is capable of inspecting any complexly shaped objects since it is noncontact scanning, and (3) a wide range can be inspected quickly since it is high-speed scanning using mirrors] that are unseen in conventional ultrasound inspection technology. We thought a new field of inspection could be cultivated, and embarked on product realization of a device that is portable and easily operable. The assumption is based on the voices of the inspection market that "only about $10-20 \%$ of the places we'd like to inspect can be inspected with the current nondestructive inspector, because we're inspecting only the places which can be inspected."

For the carbon nanostructure cold cathode X-ray, there was a demand that one wished to inspect the changes, corrosion, and damage over time of objects with a compact and lightweight device that can be transported to the spot to conduct inspection on site. Therefore, we incorporated carbon nanostructures that were being developed originally as light source to the cold cathode electron source of the X-ray tube, and succeeded in achieving practical level X-ray output. Moreover, compared to the Hot cathode, there were many advantages including the following: it is compact and lightweight, requires no preheating or standby voltage, can conduct instant irradiation, is energy saving so it can be operated by a dry cell, and has a long lifespan.

\section{Approach when overcoming difficulties Question \& Comment (Keiichi Ikegami)}

Even if you obtain the basic technology through technological transfer from AIST, it doesn't mean that you've made a product that is acceptable to the market. For example, in the case of LUVI, in research, parts such as a laser and a piezoelectric receiving sensor may be selected focusing only on performance at a public research institute, but in case of commercialization, I imagine it was necessary to select and combine optimal parts while considering cost. What were the difficulties that arose during the process, and what kind of background and approach did you have when overcoming the difficulties?

Answer (Bo Wang, Junji Takatsubo, and Norio Saito)

In the development of LUVI, we were forced to spend time on improving the synchronizing precision of laser irradiation, mirror scanning, waveform recording, reduction of electric noise during single measurement, and development of extraction algorithms for defect echoes from the measured images. On the other hand, there was a dilemma that the cost would increase if the performance and precision were increased, and we struggled on how to make an inexpensive, light, small, and tough product while satisfying the users in performance and precision.

For the carbon nanostructure cold cathode X-ray, the components including the carbon nanostructure cold cathode electron source, the cold cathode X-ray tube to which it is incorporated, and the circuit that is operated by dry cells did not exist, and we had to create them for the first time in the world. It was trial-and-error and repetition of prototyping and experimenting, and it was a continuous challenge while building on our findings. Using those findings, we continued development toward practical application, from low tube voltage to higher tube voltage.

\section{Ultralow loss multistage booster circuit in the cell- operated compact X-ray inspector \\ Question \& Comment (Keiichi Ikegami)}

Regarding the cell-operated compact X-ray inspector, I think the development of an ultralow loss multistage booster circuit must have been a major hurdle. For plant piping inspection, I believe you had the choice of installing a large power source in the controller side (that can be placed at a distance of $20 \mathrm{~m}$ from the $\mathrm{X}$-ray source), but what were your thoughts and background that made you opt for downsizing the power source as well? Also, did you encounter major difficulties in developing the booster circuit? Answer (Bo Wang and Norio Saito)

We initially started the development of a cell-operated compact X-ray inspector because there was a demand for a compact and lightweight X-ray source that fit in the narrow space between the plant pipes. The demand was also that it ran on dry cells or battery units, so it could be used on site even without an AC $100 \mathrm{~V}$ power source, while being compact and lightweight. Therefore, the booster circuit was made as a multistage system that could boost the voltage from about $1.5 \mathrm{~V}$ of one dry cell to about 60 to $100 \mathrm{kV}$. We repeated the prototyping and experimenting until the desired tube voltage was obtained, and finally arrived at an ultralow loss multistage booster circuit.

\section{Work on new fields}

\section{Question \& Comment (Keiichi Ikegami)}

In developing the self-propelled compact X-ray inspector for power lines, I think the weight reduction and setting three sets of FPD and X-ray sources to photograph the entire circumference at once would have been conflicting elements. I imagine that the new development of a booster circuit was one way to overcome this difficulty, but did you have any other innovation such as in the selection of parts? Also, the self-propelling mechanism seems to belong to a field different from the one that your company specializes, but was there any difficulty in its development?

\section{Answer (Norio Saito)}

For the development of a self-propelled compact X-ray inspector for power lines, first, several years were taken to downsize the carbon nanostructure cold cathode X-ray tube. Since the existing detector was too big, we obtained three detector elements and worked hard on originally developing the detection circuit. Through such efforts, we were able to downsize the device even with three sets. Also, through new development of the circuit, we could efficiently drive the three sets. For the selfpropelling mechanism, it was a new challenge, and we selected a compact and optimal motor by driving torque, and created simulated power lines within the company to ensure control during scanning. We placed the device on this mechanism and conducted experiments to perfect the device. 